\title{
ESCRIBIR EL PASADO, YENDO AL FUTURO
}

\author{
Anna CABALLÉ \\ Universidad de Barcelona \\ A Ernest Lluch \\ In memoriam
}

Es un hecho evidente que en el último cuarto de siglo el memorialismo español ha experimentado un auge espectacular. La muerte de Franco, el 20 de noviembre de 1975, selló definitivamente una larga etapa de nuestra historia más reciente. Una etapa que se había iniciado en 1936 y que culminó con la derrota republicana y la implantación de un régimen autoritario, represor y dogmático que arrasó con la vida intelectual y moral que, a trompicones, se había empezado a desarrollar en las primeras décadas del siglo. Desde entonces, desde la muerte de Franco (que no del franquismo porque su desaparición no debió ser tan automática como para esfumarse ideológicamente de un día para otro) los españoles tenemos una enorme necesidad de que otros digan, recuerden, lo que nuestra cultura y nuestra sociedad han sido bajo las grandilocuentes y estúpidas proclamas que sirvieron para deformar durante tantos años la vida cotidiana.

Es probable que sea una necesidad nunca satisfecha del todo, insaciable, voraz a la hora de reescribir una y otra vez la historia inmediata de España. Los historiadores se han entregado a fondo a dicha labor, es cierto, y han estudiado tanto las circunstancias políticas, los hechos de la guerra y la represión posterior, como los acontecimientos que condujeron a la contienda. Lo han hecho, aunque no de una forma libre de prejuicios ideológicos y políticos. Pero, en cualquier caso, la memoria personal es otra cosa y su espacio de expresión también es otro y distinto del espacio que ocupa la memoria histórica. Tiene que ver con la rees- 
critura del pasado inmediato en tanto que enraizado en la propia biografía y cuya comprensión es, por tanto, necesaria para dotar de sentido a la vida individual. El régimen de Franco fue, sobre todo, un colosal enmascaramiento de la realidad, dicho en palabras del siempre ecuánime Julián Marías y la necesidad de desenmascarar dicha realidad para hacerla vivible y civilizada no puede posponerse una vez desaparece la figura del dictador, y desde entonces. (A ese enmascaramiento de la realidad y a sus consecuencias expresivas se refiere también Gonzalo Torrente Ballester en sus Cuadernos de la Romana, por citar a un escritor que conoció bien y por dentro los entresijos del franquismo).

En palabras, éstas más contundentes, del memorialista Felip Cid y que traduzco del catalán:

El impacto que todo esto provocó, el escenario de la derrota, las formas de vida cotidiana dominadas por una irracionalidad con tufo de cuartel y complicidades eclesiásticas, estos hechos fueron íntimamente devastadores. Capaces de aniquilar, de triturar en mil pedazos indignos a cualquier persona mínimamente civilizada. (Memòries inútils).

La siguiente es de un libro memorable: El hombre indigno, de Antonio Rabinad:

Si intento recordar la España de los años cuarenta -o más exactamente la que va desde el Año de la Victoria hasta la huelga de tranvías en Barcelona- lo primero que noto es un silencio sepulcral. En esa España todo suena como a través de un acolchado profundo, de un espeso cortinaje (...) La impresión general era la de estar muerto.

Otra cita del republicano Nemeso Reposo, repatriado a principios de 1942. Después de pasar unos meses en la Modelo se le deja en libertad. En sus memorias escribe sus primeras impresiones al llegar a la capital catalana:

Barcelona parece una ciudad quieta, no hay bullicio, el movimiento es escaso comparado con sus mejores épocas de gloria. Dicen que hay hambre en los hogares, yo noto tristeza en los rostros.

Otra más de Carlos Castilla del Pino, autor de una valiosísima autobiografía, Pretérito imperfecto. Se refiere también a los años 40 en Madrid, cuando el autor estudiaba medicina en una más que precaria universidad:

No se hablaba de política en la facultad (...) La reserva sobre las situaciones familiares o el mutismo sobre posiciones políticas anteriores se mantenía incluso con los amigos, como lo prueba el que yo ignorase todo sobre dos 
compañeros de facultad con los que entablé una estrecha relación y con los que mantuve durante la carrera contacto al principio casi diario, luego diario.

Y una última cita de Años de penitencia, el primer volumen de memorias de Carlos Barral, un libro de prosa deslumbrante y de grandísima influencia en el desarrollo posterior del género. Reparemos en que el franquismo aparece ya cristalizado -me refiero sólo a la literatura memorialística- como una enorme, inmensa cucaracha de resonancias kafkianas (las memorias de Barral se publican en 1975):

Lo que me empujaba a escribir -anotará en el prólogo el poeta - era el deseo de representar, con frialdad y con distancia, si hubiera sido posible, mi memoria ya depositada de aquel mundo sórdido, de aquella interminable década como inscrita, toda ella, en el lomo de una repugnante cucaracha, grande como el mundo mismo.

Reconstruir lúcidamente las repercusiones de ese impacto (Felip Cid), de esa muerte (Antonio Rabinad), de esa tristeza en los rostros (Raposo), de esa reserva (Castilla del Pino), del enmascaramiento pertinaz (Marías, Torrente), de esa enorme, inmensa cucaracha (Barral), se ha convertido en una asignatura todavía pendiente (no es la única), sobre todo, y en el momento actual, para la generación nacida en torno a 1930. Y es por ello que los libros de memorias proliferan haciendo uso de un espacio de libertad y de una relativa independencia moral como es el desarrollado en la escritura autobiográfica de los últimos años, al margen de los códigos de silencio impuestos en la transición democrática y sobre cuya incomprensible pervivencia se viene discutiendo ampliamente en los últimos tiempos.

La memoria biográfica tejida en los últimos 25 años no ha alcanzado todavía, en líneas generales, a volcarse en escritura: cuando eso ocurra tendremos ocasión de reparar los vacíos ahora existentes. A tenor de la dinámica imperante entre nosotros, a la escritura de la transición, vivida como experiencia personal antes que colectiva, le faltan todavía unos años para ir tejiendo las múltiples hebras que puedan explicarla con claridad. Otra cosa es que la recepción crítica (que no lectora) de la autobiografía sea tan precaria en nuestro país que buena parte de ese corpus memorialístico generado a partir de la transición y ubicado en un tiempo anterior no tenga por el momento la valoración interpretativa que merece'.

Me limitaré a señalar un ejemplo: el artículo de Angel Basanta y Angel G. Loureiro en Ínsula: «La autobiografía desde 1975» donde se repasa descuidadamente la producción autobiográfica en español desde esa fecha. Al comienzo del artículo sus autores dicen prescindir de cualquier premisa científica (¿por qué?) y parten de una observación desconcertante y paradójica: dado el carácter ilu- 
Pero vayamos al pasado. Entre 1936 y 1939, muchos poetas, escritores, cientíticos y artistas no tuvieron opción a la hora de tomar el camino del exilio dado su compromiso político con el régimen legítimamente constituido de la II República. Cuando Pedro Salinas, uno de los primeros en salir del país (estuvo al frente de la UIMP en Santander hasta el 29 de agosto de 1936), visita México en 1939 escribe a su gran amigo y corresponsal Jorge Guillén, le habla con gran frialdad y distanciamiento, casi desprecio, de ese exilio que ha podido comprobar por sí mismo:

Y por fin llegué a la capital (de México). Y allí se acabó el turismo y no vi más ruinas que las numerosas de los españoles en el destierro. Emigrados por todas partes, y de toda condición, desde el científico de la Junta, al poeta moderno. Pequeña lista: Canedo, Lafora, Enzina, Salazar, Bal y Rosita, Recaséns, Gaos, Moreno Villa, Bergamín, Ugartye, Prados, Gaya, Gil-Albert, Petere, Jarnés, Ontañón, Madinaveitia, Giral, Joaquín Xirau, Carner, y ... Domenchina con su pareja. Casi toda la lira. Además de los políticos, y ex embajadores, que pululan².

En el exilio se escanciarán los recuerdos forzosamente amputados pero llenos de pasión por la España republicana de tantos emigrados: Juan Ramón Jiménez, Constancia de la Mora, Federica Montseny, Manuel Azaña, Rafael Alberti, $\mathbf{M}^{\mathrm{a}}$ Teresa León, María Lejárraga, Luis Cernuda, Ramón J. Sender, Luis Buñuel, Corpus Barga, Concha Méndez, Max Aub, Corpus Barga, Ramón Gómez de la Serna... No disponemos todavía de un estudio, sí de inventario, que evalúe el desarrollo de la prosa memorialística escrita en el exilio y en qué medida el progresivo alejamiento de su ideal -un regreso inminente- queda reflejado en su escritura autobiográfica. Pero, en cualquier caso, su memoria de la España real, no la recordada con nostalgia, quedó interrumpida con el exilio, de modo que sin minusvalorar en absoluto su importancia textual, hay que decir que su alejamien-

sorio de la autobiografía «toda definición de lo autobiográfico va a lindar con lo arbitrario». Efectivamente el corpus que sigue es un totum revolutum carente de rigor para concluir, de cualquier modo, que «desgraciadamente, y a pesar de las brillantes excepciones, continúa en vigor el vaticinio de Ortega, y hay que concluir que en España no existe todavía una tradición autobiográfica verdaderamente importante». Es un juicio que a estas alturas resulta incomprensible. El primero en reparar en su desatino fue Manuel Alberca en un trabajo excelente sobre las autobiografías de Caballero Bonald, Carlos Castilla del Pino, Jesús Pardo y Terenci Moix: «Los desafíos autobiográficos», en $L a$ literatura de la memoria entre dos fines de siglo: de Baroja a Francisco Umbral, 1898-1998, ed. de Miguel García Posada, Anna Caballé y J.P. Castellani, Comunidad de Madrid, 1999.

En Correspondencia (1923-1951), ed. de Andrés Soria Olmedo, Tusquets, 1992, págs. 204-205. 
to geográfico (y moral) les ha impedido a muchos de ellos contribuir a la reflexión biográfica sobre el alcance de la postguerra? ${ }^{3}$.

Entre los que se quedaron, el grado de connivencia o disidencia con el franquismo fue amplísimo y de una complejidad que no acepta el resumen, pero, en cualquier caso, la libertad de expresarse tanto en un sentido político como moral quedó prohibida formalmente el 11 de abril de 1939. Es un hecho importantísimo como veremos, pues sólo en una atmósfera de libertad y respeto por el individuo puede aflorar fluidamente la escritura de la memoria, esto es, sin coacciones que la estrangulen ${ }^{4}$.

Es por ello que la mayor parte de memorias y autobiografías publicadas en la Península entre 1939 y 1975 tiene un alcance voluntariamente reducido y alicorto. Serán libros que se centrarán en evocar etapas remotas, cronológicamente hablando, como la infancia y la juventud vividas a principios de siglo, evitando la menor referencia a la conflictiva postguerra. $O$ bien tenderán a una estilización biográfica que permita justificar la ausencia de una cronología comprometedora. Será el caso de las memorias de Camilo José Cela, la Autobiografía de Miguel Villalonga, los Recuerdos y olvidos de Jacinto Benavente, la Novela de un literato de Cansinos-Asséns, las pulcras evocaciones de Azorín, las memorias de César González-Ruano, la Crónica General de Juan Gil Albert ... todas ellas, en fin, centradas, como el memorialismo escrito en el exilio, en la vida española anterior a 1936. 1936: año cero para el memorialismo peninsular. En el umbral del siglo

'Sin embargo, en la importancia traumática del exilio y la ruptura que supuso para la cultura española no todos están de acuerdo. Para Francisco Umbral, con su actitud (juanramoniana) de críticar a los contemporáneos, en su libro memorialístico, Madrid, tribu urbana, pone en solfa una vez más y sin contemplaciones el tópico de la pérdida irreparable. El tópico que se construyó (y sigue) sobre esa pérdida, no la pérdida en sí. Por ejemplo, cuando dice:

«España se había partido en dos porque la mayoría de los literatos y poetas eran o se creían de izquierdas, y tuvieron que irse. En total suman unas docenas cortas, pero esto se consideró el hundimiento intelectual de España. Yo creo que la aparición de Cela, Buero, Bardem, Fernán Gómez y otros compensaba un poco la ausencia de Alejandro Casona, pero incluso los tres hombres/revelación (sic) que acabo de citar mantenían el mito de la España ausente.

Centrar en Casona el volumen y la importancia de los intelectuales exiliados es a todas luces excesivo, pero no me lo parece el hecho de abordar libremente (sin estereotipos ni clichés) la vida cultural española de aquellos años y enfrentarse al mito.»

${ }^{4} \mathrm{~A}$ ello se refiere, por ejemplo, Arcadi Espada cuando analiza la aportación estrictamente autobiográfica de Josep Pla. Pese al anclaje permanente en el yo, a Josep Pla le falta firmeza para encararse con la indagación de sí mismo: véase «Lagunas en la memoria planiana», La literatura de la memoria entre dos fines de siglo: de Baroja a Francisco Umbral, 1898-1998, ed. de Miguel García Posada, Anna Caballé y J.P. Castellani, Comunidad de Madrid, 1999.

${ }^{5}$ Me remito a Narcisos de tinta. Ensayo sobre la literatura autobiográfica en lengua castellana (siglos XIX y XX), Megazul, 1995. 
XXI su estudio plantea todavía problemas historiográficos de consideración. Y pondré un ejemplo.

En 1944 aparecen las memorias de Pío Baroja, Desde la última vuelta del camino, expurgadas de cualquier referencia política o vital posterior al estallido de la guerra. La impresión (que reflejé en Narcisos de tinta) es la de un vacío total sobre la vida y pensamiento del escritor vasco a partir del estallido de la guerra. Pero no es así porque en Santiago de Chile aparecieron de forma independiente sus notas sobre la guerra de España, escritas durante su refugio en Francia y tituladas Ayer y Hoy (Ercilla, 1939). En ellas Pío Baroja se muestra como un hombre agobiado por la destrucción y el odio que exhiben en uno y otro bando sus compatriotas, de modo que Baroja intenta, pese a todas las dificultades reinantes, defender su independencia y su albedrío, siempre escéptico:

En esta gran aventura revolucionaria en que se ha metido de lleno España, yo me siento incapaz de tener confianza en algo político. Es difícil que un español actual, que no sea fanático o iluso, pueda ser en estos momentos optimista.

Indispensable complemento a las notas de Ayer y Hoy son las publicadas con el título de Aquí Paris. Fueron escritas, como las anteriores, durante su exilio francés (en éstas el escritor está ya tristemente instalado en la Casa de España de París) y tratan de España y de la guerra de forma obsesiva. Pero también tratan de la soledad y del aislamiento de un hombre. En el prólogo a la edición que se hizo en 1955 de Aquí Paris, Baroja rezuma pesimismo, como siempre:

Pasan por la pantalla gris del hombre desafortunado y melancólico los recuerdos sin ilación, las imágenes puramente sensuales de la tierra y del mar, las impresiones de una noche magnífica en el Mediodía o en el Norte, con una luna o con estrellas, el monte nevado o el salón de una mujer elegante y fina.

Ya, para mí, todo ello es pura nostalgia que empieza y acaba en ella misma, y que no arrastra, ni ambición, ni ilusión, ni pretende realidades auténticas.

Ambos libros, inencontrables, los reeditó Caro Raggio en 1998 y resultan piezas insustituibles a la hora de analizar la escritura memorialística en la obra de Pío Baroja. Imposible valorar el significado de Desde la última vuelta del camino sin tener en cuenta esos dos cuadernos de notas que, probablemente, por motivos de censura no pudieron incluirse en la edición de sus apolíticas y zigzagueantes memorias.

¿Será el único caso? No es probable y una tarea pendiente es la de retribuir a los textos memorialísticos publicados entre 1939 y 1975, y que estén incom- 
pletos o amputados, los pasajes que faltan, así como recuperar los textos autobiográficos referidos a una etapa posterior a 1939 y que por razones de censura no . pudieron publicarse en su momento. ¿Es que Cansinos Asséns, magnífico cronista de la bohemia madrileña de principios de siglo, no escribió nada sobre la vida, su vida, derivada de la guerra civil? Murió el 6 de julio de 1964 en la clínica Rúber de Madrid (www.cansinos.com). ¿Qué hay de sus diarios de postguerra?

En ese contexto desleído y timorato en cuanto a una trascendente expresión del yo, y que es el imperante durante el franquismo, transcurre también, en lo que se me alcanza, buena parte del memorialismo republicano. Su rasgo dominante será el carácter marcadamente político, reivindicativo y preservador, no sólo de unas opciones políticas malogradas sino también de un modo de sentir, de pensar y de actuar. Las Memorias políticas y de guerra de Manuel Azaña constituyen tal vez el epicentro de la memoria republicana. Una memoria cada vez más nostálgica e idealizada, de configuración mítica, que alcanza la publicación de libros como La quencia de Miguel García Posada donde la nostalgia republicana se proyecta más allá de lo que permite y se explica por la propia cronología vital. Véanse también obras como El niño republicano, de Eduardo Haro Tecglen, o Adiós, luz de veranos de Jorge Semprún ${ }^{6}$.

Sin embargo, la memoria de dentro y la de fuera son lógicamente dos memorias progresivamente divergentes que apenas comparten inquietudes comunes. La queja de Max Aub en su diario La gallina ciega no puede ser más elocuente de esta quiebra: Max Aub no acierta a comprender, en su fugaz regreso a España en agosto de 1969, el olvido en que se vive respecto de la guerra civil y sus consecuencias. Habían transcurrido exactamente treinta años, los españoles (a un lado la represión socio-política en la que se vivía) que se quedaron no podían mantener eternamente la tensión emocional derivada de aquel trauma que supuso un enfrentamiento fraticida. Pero Max Aub no puede admitir que la sociedad española haya abdicado de los principios revolucionarios que habían hecho de España un punto de mira internacional. Nada más llegar al aeropuerto de Barcelona se sorprende de que nadie le dé importancia al cambio de su visado, nadie le pregunta nada, nadie le registra las maletas, ni siquiera escrutan su rostro buscando algo. Nada. El aeropuerto, por otra parte, se parece a cualquier aeropuerto europeo...

Única diferencia con Roma, Londres y París: aquí las puertas son electrónicamente corredizas. Ninguna emoción. Y, sin embargo, en estos llanos (se

${ }^{6}$ Hay que esperar a que Blanca Bravo Cela (Unidad de Estudios Biográficos) acabe su tesis sobre la configuración del mito de la República en el memorialismo español contemporáneo. 
refiere a los campos de El Prat de Llobregat) filmamos muchas escenas de Sierra de Teruel.

María Zambrano describió muy bien el doble drama del exiliado, condenado desde fuera a amar a su país desesperadamente, para comprobar, cuando puede regresar a él, que no le han dejado sitio alguno7. Sin embargo, es una experiencia de desarraigo de la que también se quejan muchos españoles ahora mismo a los que el estado democrático mantiene en un olvido absoluto, pese al heró́smo con el que combatieron en contra de la dictadura. Por poner un ejemplo: Lidia Falcón en sus sobrecogedoras memorias Los hijos de los vencidos. No hay justificación, escribe la feminista, para la marginación brutal en que se tiene a quienes de modo más firme lucharon en la oposición al franquismo.

El punto de inflexión en el desarrollo de la prosa memorialística española, radicalmente escindida entre la que se escribe en el interior y la que se escribe en el exilio, es, decíamos, el año 1975. El año tiene, lógicamente, un altísimo valor simbólico y significa mucho. Así lo ve Julián Marías en el tercer volumen de Una vida presente:

En la vida nacional se ha producido desde fines de 1975 una evidente aceleración; hasta entonces parecía que «no pasaba nada», lo cual era evidentemente falso: pasaba el tiempo, el tiempo de nuestras vidas; desde esa fecha han pasado y siguen pasando muchas cosas, la vida pública ha adquirido un argumento que antes también existía -he tratado de mostrarlo- pero no era aparente.

Marías habla de una vida política que ya existía pero que «no era aparente». Diría que es un juicio razonable pero insuficiente, puesto que la represión cultural y política ejercida sobre generaciones de españoles causó un daño irreparable. Que latía una vida, incluso pública, por debajo de la oficial no significa que esa forma farisaica de vivir fuera la deseable. No lo era. Y tampoco significa que una vez desaparecido el dictador, y los flecos que le colgaban, gracias a una especie de performance colectiva aflorara todo lo oculto sin más. El perjuicio fue irreparable en muchos sentidos y ésa es precisamente una notable preocupación de muchos memorialistas actuales a la hora de escribir las memorias de aquellos años. Es una clara preocupación de Terenci Moix, por ejemplo, en el primer volumen, y soberbio, de su autobiografía, El peso de la paja, titulado El cine de los sábados (1990). Terenci Moix, treinta y tantos años después, no perdona a sus mayores ni olvida el abismo que de forma tan irresponsable abrieron en su infancia. Una educación suspicaz, falsaria y tartufesca le arrojó al único espacio posi-

\footnotetext{
${ }^{7}$ Véase Delirio y destino (Los veinte años de una española), Mondadori, 1989.
} 
ble de rebeldía: la literatura. Sin embargo, la nostalgia del aprendizaje, la falta de un modelo educativo en el camino vital es para el narrador de El cine de los sábados un vacío irreparable. Pasajes conmovedores de esa falta de sintonía entre las necesidades de un niño despierto y la estupidez reinante abundan en el libro. Me quedo con uno: Terenci Moix tiene 12 años y es un apasionado del Antiguo Egipto, aunque nadie se lo toma en serio. En una clase un profesor le descubre en el pupitre y entre los libros de texto una novela que al joven Ramón había deslumbrado: Sinuhé, el egipcio, de Milka Waltari. Empiezan los interrogatorios típicos sobre los actos impuros, primero en un despacho, después en el confesonario donde el sacerdote que le interroga no cede en su propia lascivia acosándole para que diga lo que espera que le diga:

Así aprendí a desconfiar de otro sacramento, como ya había aprendido a prescindir de las glorias anunciadas en la comunión. $Y$ todo por un cura tonto, incapaz de comprender que a un niño de doce años pudiera interesarle mucho más la historia de Tebas durante la XVIII dinastía que las porquerías de una puta babilónica llamada Nefernefernefer.

La autobiografía de Terenci Moix (lleva publicados tres volúmenes hasta la fecha) ha sido, dicho sea de paso, una de las más transgresoras de todas las publicadas en el ámbito hispánico (sin que ello signifique olvidarse de Coto vedado de Juan Goytisolo). Entre otras cosas, por la libertad que manifiesta el escritor en la expresión de una subjetividad disidente y homosexual. Pero los tabúes que rodean dicha expresión son de tales dimensiones que la escritura autobiográfica de Moix no puede sustraerse a la parodia y a la autoironía para aliviar la tensión de su voluntad transgresora y la «obscenidad» con que para muchos fue recibida la extrema sinceridad del escritor consigo mismo. «Nos creemos sofisticados y jugamos a reírnos de nosotros mismos, pero en el fondo lo que nos gustaría es estar más seguros», escribió Jaime Gil de Biedma en El pie de la letra, de 1980. Pues bien, esta seguridad que el poeta admitió echar de menos, demuestra tenerla Terenci Moix forzando sus límites hasta el extremo de convertir la escritura autobiográfica en acto, es decir, en compromiso. Me remito al magnífico trabajo sobre Moix (y otros) de Manuel Alberca «Los desafíos autobiográficos», ya citado.

Lo cierto es que en un sentido puramente bibliográfico, en los aledaños de 1975 se produce ya el cambio de estilo, el desarrollo de lo que podríamos denominar una genuina actividad autobiográfica. Que en un primer momento muchos orientaron a la exposición de las «leyes interiores», digámoslo así, que habían dominado su vida anterior (es decir, en vida de Franco). Aquí está el tempranísimo alivio de Laín Entralgo que abrió el fuego con su libro Descargo de conciencia (1930-1960). Un libro de estilo ampuloso y complaciente que se propone, sin 
embargo, como un «leal ejercicio de la palinodia», es decir de autocrítica, dada la estrecha colaboración de Laín con el franquismo y la falta de sostén intelectual y moral que caracterizó la dictadura franquista en sus últimos años. Ridruejo, Laín Entralgo, Rosales, Vivanco, Tovar, Gonzalo Torrente, Rodrigo Uría, ... formaron el núcleo germinal de la intelligentzia nacional que había actuado de forma decidida en Burgos a través del Servicio Nacional de Propaganda del incipiente Nuevo Estado. Su posición, se ha dicho, quedó pronto orillada frente a otros planteamientos más integristas y menos intelectuales. Laín insiste en su libro en la guetización que sufrió el falangismo más puro y el uso interesado que se hizo de él desde el principio (véase la réplica en la Leyenda del César visionario, de Francisco Umbral, o con una intención muy distinta en Pretérito imperfecto, de Carlos Castilla del Pino). El libro de Laín a nadie pudo convencer de que el conocido humanista buscaba otra cosa que la justificación moral del propio compromiso con un Régimen en vías de desmoronamiento.

Las memorias de Dionisio Ridruejo se habían empezado a escribir mucho antes -de hecho Laín se propone seguir la estela autoexculpatoria iniciada precozmente por el que fuera responsable de la propaganda del Nuevo Estado-, como artículos sueltos y sin sujeción a ningún orden cronológico. Ridruejo consideraba esta labor de recopilación como preparatoria («una avanzadilla», dirá) de su intención de escribir más adelante unas memorias que nunca llegaron a ser:

Aquí y ahora, sólo puede contarse una pequeña parte de lo vivido, y por añadidura resultaría impertinente la exposición de la urdimbre intimista y más personal sobre la que la trama de los sucedidos ha de pasar para componer el tapiz de un libro con unidad biográfica de sentido (pág. 21)

(La subordinación o elipsis de la vida personal en beneficio del relato históricamente relevante expuesto por Ridruejo no es nuevo, como sabemos. De hecho, forma parte de nuestra particular «poética» autobiográfica, siempre dispuesta al understatement, al «decir de menos» como precepto intelectual. Los orígenes de ese código verbal basado en el decoro y la corrección en la expresión personal son tan lejanos como inciertos por la pluralidad de razones que permiten explicarlo. Y que siguen funcionando: no hay más que ver las burlas y suspicacias que despiertan quienes intentan ser sinceros consigo mismos y con los demás. Por eso es tan importante, en mi opinión, el desarrollo de los géneros de

${ }^{8}$ La actividad autobiográfica de Ridruejo ha sido bien estudiada por Danielle Corrado. Sus trabajos más recientes: «Los diarios de Dionisio Ridruejo», en La literatura de la memoria entre dos fines de siglo: de Baroja a Francisco Umbral, ya citado, págs. 91-112 y Le journal intime en Espagne, Publications de l'Université de Provence, 2000. 
la memoria entre nosotros, tal como se viene produciendo en los últimos años. El espacio que genera su escritura va mucho más allá del acopio de datos sobre el sujeto que escribe y su época, es un espacio estético y moral útil para elaborar, reproducir y transformar una identidad colectiva. ${ }^{9}$ )

Sea como fuere, la salud quebradiza de Dionisio Ridruejo impidió que ese proyecto biográfico viera la luz más allá de los materiales publicados de forma póstuma en 1976, poco después de su muerte (ocurrida en Madrid, el 29 de junio de 1975 de un infarto de miocardio).

Barral, Laín, Ridruejo... son las primeras manifestaciones de una escritura memorialística que se atreve a expresar públicamente la disidencia, en mayor o menor grado, con el inmediato pasado. En esta línea estarán las interesantes Memorias y esperanzas españolas de José Luis L. Aranguren, los confusos Cabos sueltos de Tierno Galván o las memorias de Julián Marías, Una vida presente, ajustadas a una preocupación ética que impide a Marías la menor frivolidad.

\section{YENDO AL FUTURO}

Hasta aquí hemos descrito la necesidad de confrontar personalmente el recuerdo de una época, necesidad insobornable en el espacio memorialístico actual aunque no siempre resulte ser un ejercicio bien comprendido $^{10}$. Y es que

"Interesante, en este sentido, el artículo de Susana Reisz «Hablar de sí» sobre el desfase, la tensión, el forcejeo, que se da entre el hecho, que puede ser trivial, de asumir una escritura del «yo» y hablar de sí verdaderamente. Lo primero es una convención literaria mientras que lo segundo constituye una experiencia radical que puede resultar angustiosa. De un pasaje de su artículo extraigo la idea de la autobiografía como motor de transformación de la identidad colectiva, que Reisz aplica al discurso femenino fundamentalmente. Escrituras del yo. España e Hispanoamérica, Rosalba Campra y Norbert von Prellwitz (coords.), Roma, Bagatto Libri, 1999.

"Un dossier reciente titulaba los artículos recogidos en su publicación en torno a biografías y memorias: «La memoria como arma arrojadiza» con ganas de subrayar sólo un aspecto tangencial y prescindible tal vez de la memoria: su carácter revanchista. El motivo: las figuras de Ortega y Gasset, Tierno Galván y Jorge Semprún sacudidas por la mirada crítica de Gregorio Morán, César Alonso de los Ríos o Marguerite Duras. ¿Arma arrojadiza? Memoria sí, venganza no. ¿Es que libros como Un maestro en el erial o La verdad sobre Tierno Galván no pueden considerarse como muestras de una voluntad de contribuir al esclarecimiento de nuestro pasado, a través de la reconsideración de algunos de sus personajes más emblemáticos, antes que sospechar de su malévola intención? ¿Es que acaso es preferible el cultivo de la estatua -Ortega y Gasset, Tierno Galván- a la manera franquista antes que conocer qué guarda la estatua en su interior cuando ese interior, en cierto modo, nos afecta a todos? ¿No interesa analizar las discontinuidades, humanísimas, entre realidad y apariencia? 
escribir el pasado es un proceso activo y dialéctico: obra de arqueología e ingeniería al mismo tiempo, como ya escribió Juan Goytisolo en Coto vedado". Sin embargo, la idea central de este trabajo es subrayar el valor trascendente de la literatura de la memoria: un espacio imprescindible para comprender la dialéctica yo/mundo en medio de la cual transcurre la vida del ser humano. Quiénes somos y de dónde venimos, en palabras de Rubén. No hay modo de saberlo sin inquirir qué hemos sido en relación al mundo en que hemos vivido. Y cómo la elaboración honesta de la memoria de lo vivido repercute en la construcción del futuro (un futuro, no cualquier futuro), de modo que la función y responsabilidad de una autobiografía va mucho más allá de ser un género depositario de una experiencia personal. La literatura autobiográfica es también un indicio sólido de la forma en que un hombre, una mujer, una sociedad, encaran el porvenir. El franquismo trajo consigo una especie de impotencia autobiográfica. Como si la concepción del propio yo que lleva consigo toda autobiografía no pudiera separarse de la visión de una sociedad. Cuando la visión de esa sociedad está velada o enmascarada, el compromiso estético con la individualidad no resulta posible.

"El narrador de Coto vedado (1985) vuelve a la Universidad de Barcelona, años después de pasar por sus aulas como estudiante de Derecho. Goytisolo busca ansiosamente instantáneas, retales de recuerdos que le permitan evocar aquel muchacho de entonces. Lo ve:

«Zapatos: negros. Color del terno: beige o gris perla. Un abrigo ajustado y guantes del mismo color que el traje, como convenía a un futuro diplomático».

Se recuerda tímido y vulnerable en aquel patio de Letras y escribe:

«Vana tentativa de tender un puente sobre tu discontinuidad biográfica, otorgar posterior coherencia a la simple acumulación de ruinas: buscar el canal subterráneo que alimenta de algún modo la sucesión cronológica de los hechos sin saber con certeza si se trata de la exhumación de un arqueólogo u obra flamante de ingeniería», Alianza, Biblioteca JG, 1999, pág. 174. 